\title{
The Prevalence of Beta-Blocker Use Among Medical Students at King Saud bin Abdulaziz University for Health Sciences in Jeddah, Saudi Arabia: A Cross-Sectional Study
}

\author{
Rawan Alkhatabi ${ }^{1}$, Joud Alowfi ${ }^{1}$, Layan Arshad ${ }^{1}$, Muhammad A. Khan ${ }^{2}$ \\ 1. Medical Education, College of Medicine, King Saud Bin Abdulaziz University for Health Sciences, Jeddah, SAU 2. \\ Epidemiology and Public Health, King Saud Bin Abdulaziz University for Health Sciences, Jeddah, SAU
}

Corresponding author: Rawan Alkhatabi, rawankhalid96@gmail.com

\section{Abstract \\ Objectives}

The aim of this study was to evaluate the prevalence and patterns of beta-blocker usage among medical students. Reasons for the use and demographic factors influencing their consumption were also evaluated.

\section{Methods}

This was an observational cross-sectional study among medical students at King Saud bin Abdulaziz University for Health Sciences (KSAU-HS) Jeddah, Saudi Arabia. Medical students were surveyed between February and April of 2019 using an electronic self-administered questionnaire. The questionnaire had close-ended questions, 18 of which were about demographics and 17 about propranolol use.

\section{Results}

A total of 234 medical students participated in the study, of whom 14.5\% (95\% CI: 10.44-19.49) reported using propranolol. Fifth-year medical students comprised $50 \%$ of propranolol users. The prevalence of males using propranolol was lower compared to females. The most common reasons for using propranolol were anxiety relief and performance enhancement before the objective structured clinical exams (OSCEs; 70.6\%) and before oral presentations (38.2\%).

\section{Conclusion}

The prevalence of propranolol use among medical students in KSAU-HS Jeddah was low compared to other studies, with the highest reported use among fifth-year medical students. The main reasons for using propranolol were anxiety relief during OSCEs and performance enhancement for presentations. Efforts must be directed towards raising medical students' awareness of the risks of inappropriate beta-blocker use to

Received 03/16/2020 Review began 03/25/2020 Review ended 11/11/2020 Published 11/11/2020

๑) Copyright 2020 Alkhatabi et al. This is an open access article distributed under the terms of the Creative Commons Attribution License CC-BY 4.0., which permits unrestricted use, distribution, and reproduction in any medium, provided the original author and source are credited.
Categories: Medical Education, Epidemiology/Public Health

Keywords: propranolol, saudi arabia, medical students, beta blockers

\section{Introduction}

Medical students are prone to stress and burnout due to increasing academic demands, financial struggles, and social issues $[1,2]$. These factors can affect academic performance negatively, leading to more distress [3]. Current literature demonstrates that there are higher rates of psychological stressors among medical students compared to the general population [4]. A study in Lithuania found that symptoms of anxiety were prevalent in $43 \%$ of medical students [5]. A meta-analysis conducted by Rotenstein et al. reported a prevalence of depressive symptoms and suicidal ideation of $27.2 \%$ and $11.1 \%$, respectively [6]. Similarly, in a cross-sectional survey among senior medical students in New York, 71\% of students met the criteria for burnout [7].

Non-selective beta-blockers are used to manage performance-only social anxiety disorder (SAD), of which propranolol (Inderal) is the most commonly prescribed [8,9]. Propranolol exerts its action by inhibiting sympathetic input to the cardiovascular system, decreasing heart rate, and contractility [10]. This makes propranolol effective in decreasing the physical symptoms of anxiety $[10,11]$. According to a study in Switzerland, $13.8 \%$ of participating university students reported using prescription drugs for neuroenhancement. The most frequently used prescription medications in the study were methylphenidate (4.1\%), sedatives (2.7\%), and beta-blockers (1.2\%) [12].

University students experience high levels of stress during oral and written examinations, and agents like 
propranolol are commonly used among such populations [12]. A local study among medical and dental students in Saudi Arabia found that around 30\% used propranolol, of which $48 \%$ self-prescribed the medication [13]. Self-prescription of beta-blockers makes users more predisposed to the established adverse effects such as hypotension, bradycardia, bronchospasms, and hypoglycemia due to the lack of proper evaluation and supervision [14]. The main objective of this study was to determine the prevalence of betablocker use among medical students at King Saud bin Abdulaziz University for Health Sciences (KSAU-HS), Jeddah, Saudi Arabia. A secondary objective was to determine the causes of beta-blocker use among the same population.

\section{Materials And Methods \\ Recruitment of participants}

This was an observational, cross-sectional study among medical students of KSAU-HS Jeddah. It was conducted from February 2019 to April 2019. All medical students had an equal opportunity to participate in the study, and there were no exclusion criteria. This includes medical students from basic years, which are second to fourth year, and clinical years, which are from fifth to sixth year. The data were collected using a non-probability convenience sampling technique. The calculated sample size was 255 students, and 234 responses were included in the study.

\section{Questionnaire}

Students were surveyed using an online self-administered English questionnaire developed by the researchers. After validating the questionnaire through face validity, content validity, and pilot testing, it was sent to eligible participants electronically through email and a messaging service application. It consisted of 36 multiple-choice questions divided into three sections. The first section inquired about demographic information and baseline characteristics of the participants such as age, gender, and academic level. The last question of the first section inquired about the use of propranolol, and based on the answer to this question, they were directed to either of the following sections. Section two inquired about whether they were offered or recommended to use propranolol. While section three inquired about the details about the use of propranolol, such as prescription, frequency, and side effects.

\section{Data analysis}

Data were collected and entered in a Microsoft Excel sheet, and then exported to the Statistical Package for the Social Sciences (SPSS version 20, IBM, Armonk, USA) for the statistical analysis. Qualitative variables were reported as frequencies and percentages, and quantitative variables, such as age, were represented as means and standard deviations. The Chi-square test was used to compare the association of beta-blocker use among gender subgroups. The results were considered statistically significant if $\mathrm{p}<0.05$, and were reported with a $95 \%$ confidence interval.

\section{Ethics and consent to participate}

This study was approved by the Institutional Review Board (IRB) of King Abdullah International Medical Research Center (KAIMRC) in the Western region (Approval: SP18/522/J). Additionally, a consent form, which included the aim and objectives of the study, was required prior to participation. Privacy and confidentiality were ensured during the collection and management of the data. No personal information, such as names or contact information, were collected.

\section{Results}

\section{General results}

The included sample size was 234 students who responded to the survey, with a response rate of $94.9 \%$ (Figure 1). 


\section{Cureus}

Calculated Sample Size $(n=255)$

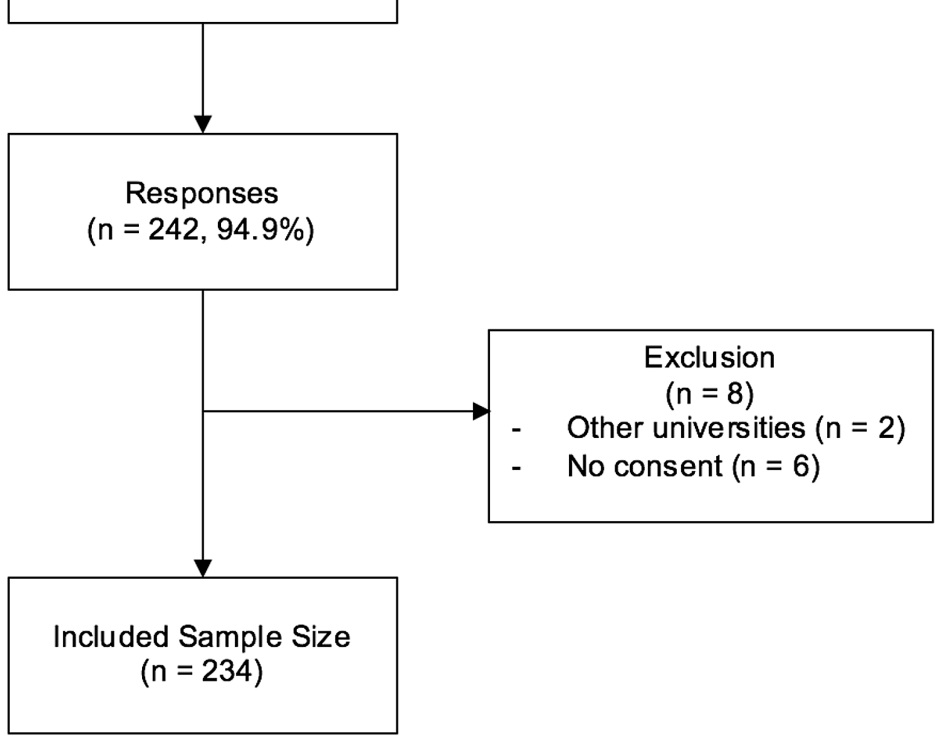

FIGURE 1: Participants Selection Criteria Flow Chart

The demographic information and baseline characteristics are summarized in Table 1 . Of the 234 participants, 34 (14.5\%) reported using propranolol. The highest rate of propranolol use was among fifthyear medical students, representing $50 \%$ of the group (Table 1 ). 


\section{Cureus}

Baseline Characteristics n (\%)

Characteristics

1- Gender

Male

Female

Total

2- Age (Mean $\pm S D$ )

3- Academic year

Third-year

Fourth-year

Fifth-year

Sixth- year

Total

4- GPA

$4.5-5$

$4.0-4.49$

$3.5-3.99$

$3.0-3.49$

$2.5-2.99$

Total

5- Smokers

6- Use of psychoactive drugs

7- Use of energy drinks

8- Exercising

9- Chronic diseases

10- Allergies and asthma

Allergies

Asthma

Both

Total

11- Diagnosed psychiatric disorder
Propranolol users $(n=34)$

Total participants $(n=234)$

8 (23.5)

26 (76.5)

$34(100)$

$22.15 \pm 1.96$

11 (32.4)

5 (14.7)

$17(50)$

$1(2.9)$

$34(100)$

$23(67.6)$

8 (23.5)

2 (5.9)

$-$

$33(97.1)^{\star}$

6 (17.6)

3 (8.8)

$10(29.4)$

17 (50)

5 (14.7)

7 (20.6)

2 (5.9)

2 (5.9)

11 (32.4)

10 (29.4)
64 (27.4)

$122(52.1)$

112 (47.9)

234 (100)

$22.39 \pm 2.1$

60 (25.6)

90 (38.5)

20 (8.5)

234 (100)

149 (63.7)

59 (25.2)

19 (8.1)

3 (1.3)

$3(1.3)$

$233(99.6)^{*}$

31 (13.2)

8 (3.4)

45 (19.2)

112 (47.9)

25 (10.7)

48 (20.5)

13 (5.6)

9 (3.8)

$70(29.9)$

$31(13.2)$

\section{TABLE 1: Baseline Characteristics}

The baseline characteristics of the total 234 participants, and the characteristics of the 34 out of 234 participants who answered "Yes" to using propranolol.

SD: standard deviation, GPA: grade point average.

*Not the complete number of participants due to missing data.

Moreover, female students are 4.35 times more likely to be using propranolol as compared to males students (95\% CI: 0.10-0.54, p<0.001; Table 2). 


\section{Cureus}

\begin{tabular}{|c|c|c|c|c|c|}
\hline & Yes, n (\%) & No, n (\%) & Total & p-Value & OR (CI 95\%) \\
\hline Male & $8(6.6)$ & 114 (93.4) & 122 & \multirow{2}{*}{$<0.001^{*}$} & \multirow{2}{*}{$0.23(0.10-0.54)$} \\
\hline Female & $26(23.2)$ & $86(76.8)$ & 112 & & \\
\hline Total & 34 (14.5) & $200(85.5)$ & 234 & & \\
\hline
\end{tabular}

\section{TABLE 2: Gender-Based Analysis}

Chi-square test. OR: odds ratio.

*Significant value.

When inquired about smoking habits and the use of psychoactive drugs, six participants (17.6\%) identified as smokers, and three (8.8\%) reported using psychoactive drugs. Additionally, 10 participants (29.4\%) were clinically diagnosed with a psychiatric disorder. Anxiety disorder was the most common illness reported (17.6\%).

\section{Results of using propranolol}

Twenty-three participants (67.6\%) out of the 34, learned about propranolol through friends and classmates. The participants had the option of choosing more than one answer for this question; other choices included social media, internet, family, and study materials (Figure 2).

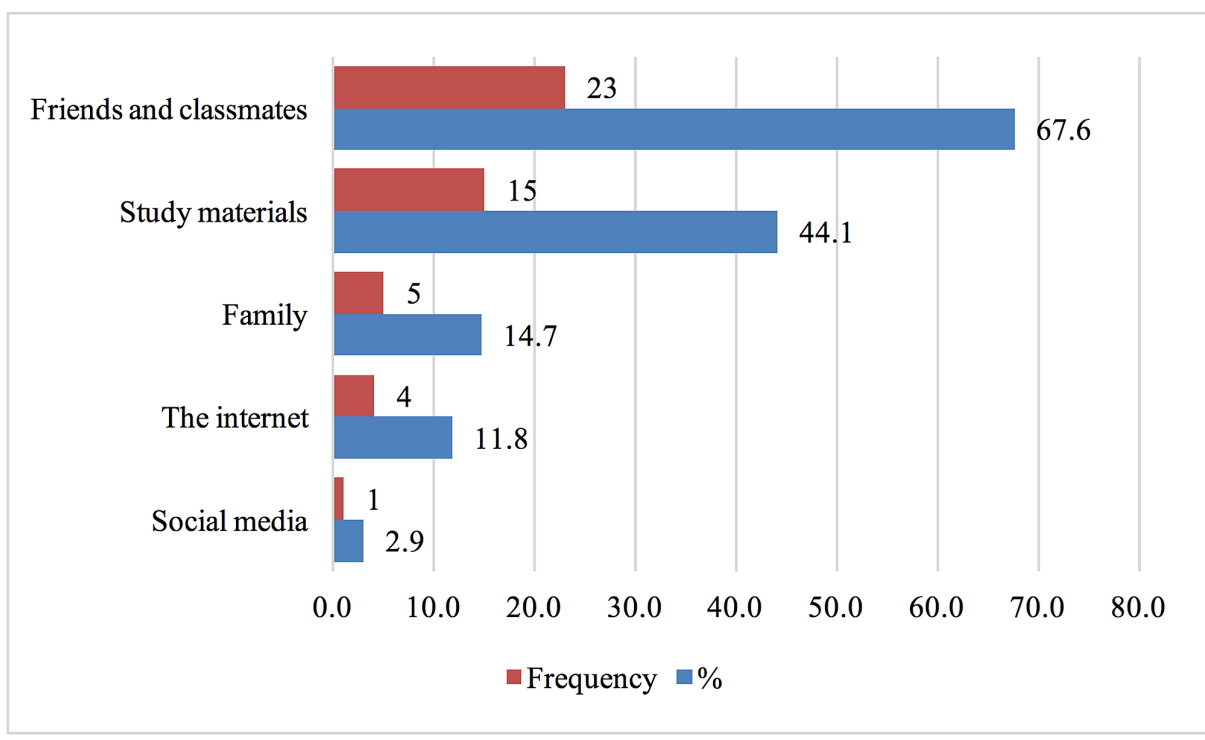

FIGURE 2: Source of Students' Knowledge of Beta-Blockers

When asked about the prescription method, self-prescription ranked first, followed by a physician's prescription (Figure 3). 


\section{Cureus}

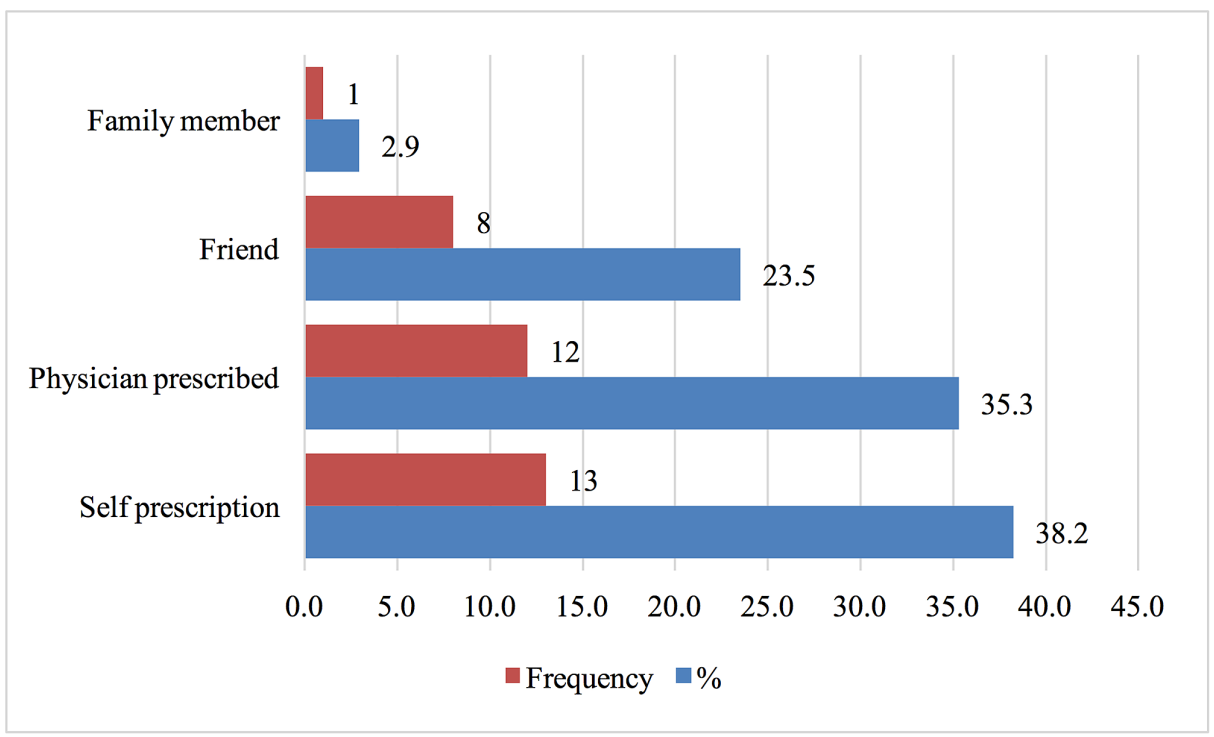

FIGURE 3: Prescription of Propranolol

The most common frequency of propranolol use was monthly in 19 participants (55.9\%), daily in five (14.7\%), rarely in six (17.6\%), and as needed in four (11.8\%). The highest reported dose was $40 \mathrm{mg}$, almost $50 \%$ of the participants consumed $10-20 \mathrm{mg}$ of propranolol as a regular dose. Ten participants (29.4\%) increased their propranolol dose without a physician's instructions.

The majority of students reported stress relief as the leading reason behind their propranolol use (82.4\%). Other responses included performance enhancement, peer pressure, and medical therapy (Figure 4).

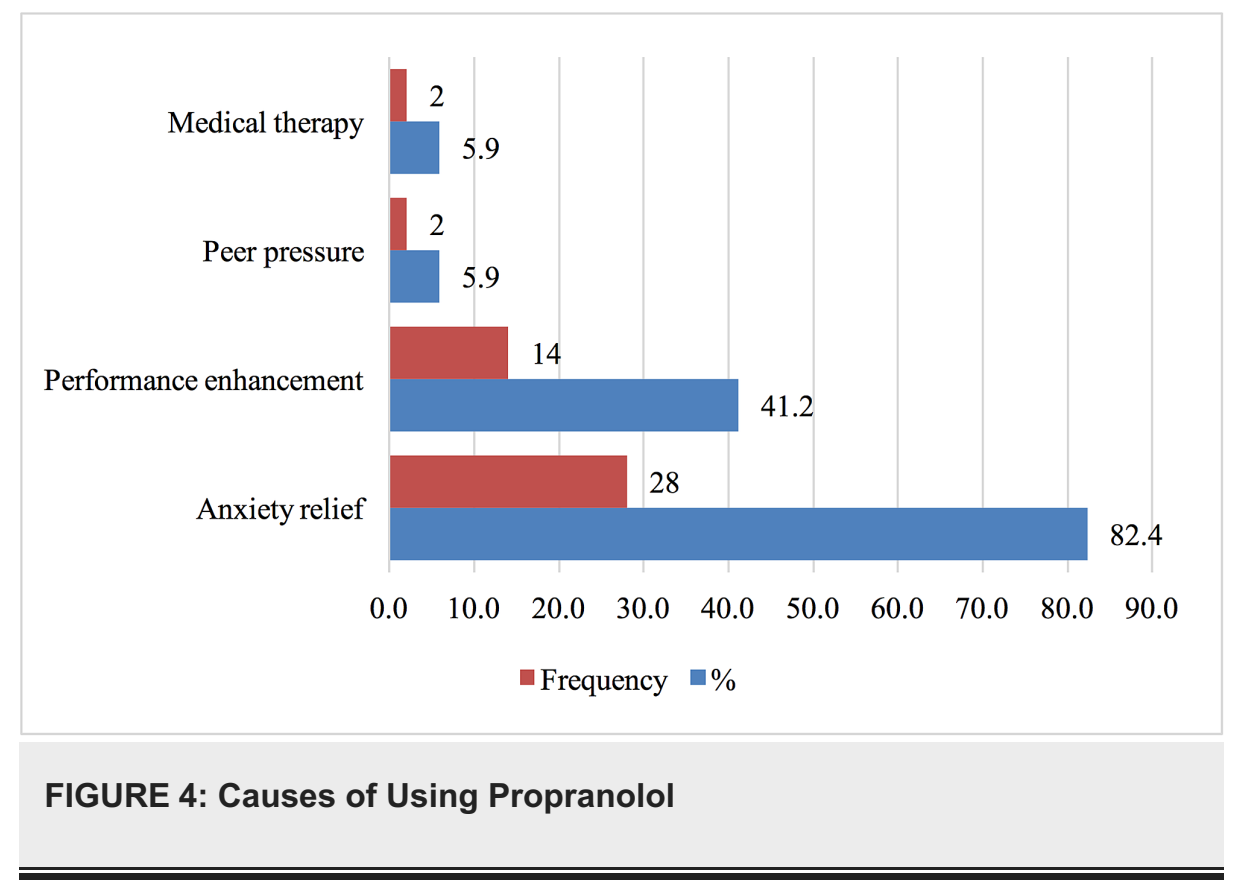

The most frequent timing of propranolol use was before OSCEs ( $\mathrm{n}=4,70.6 \%$; Figure 5). Only four participants (11.8\%) reported that they took the drug daily. 


\section{Cureus}

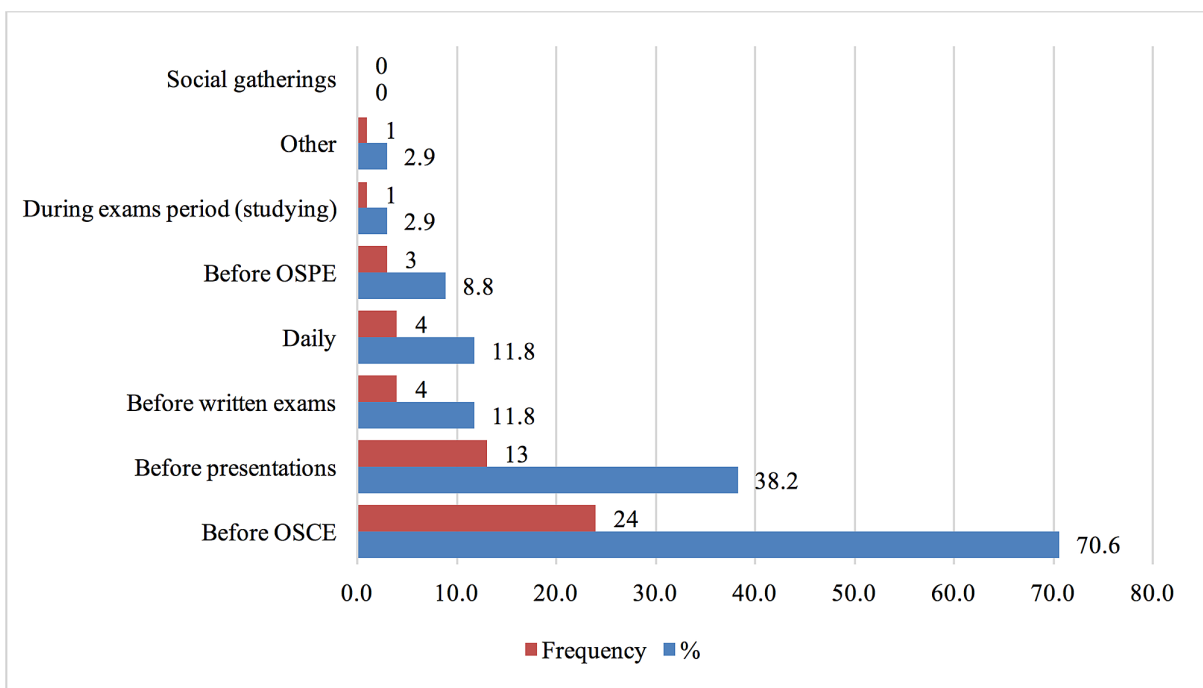

\section{FIGURE 5: Timing of Propranolol Use}

OSPE: objective structured practical examination, OSCE: objective structured clinical examination.

Twenty-seven students (79.4\%) were aware of the side effects of unsupervised propranolol use. However, only six students (17.6\%) have previously experienced side effects. As demonstrated in Figure 6, students (73.5\%) thought that propranolol improved their performance. While 29 (85.3\%) participants (17.6\%) were recommended propranolol pills by friends and classmates, 20 (58.8\%) students reported offering and recommending propranolol to friends and classmates.

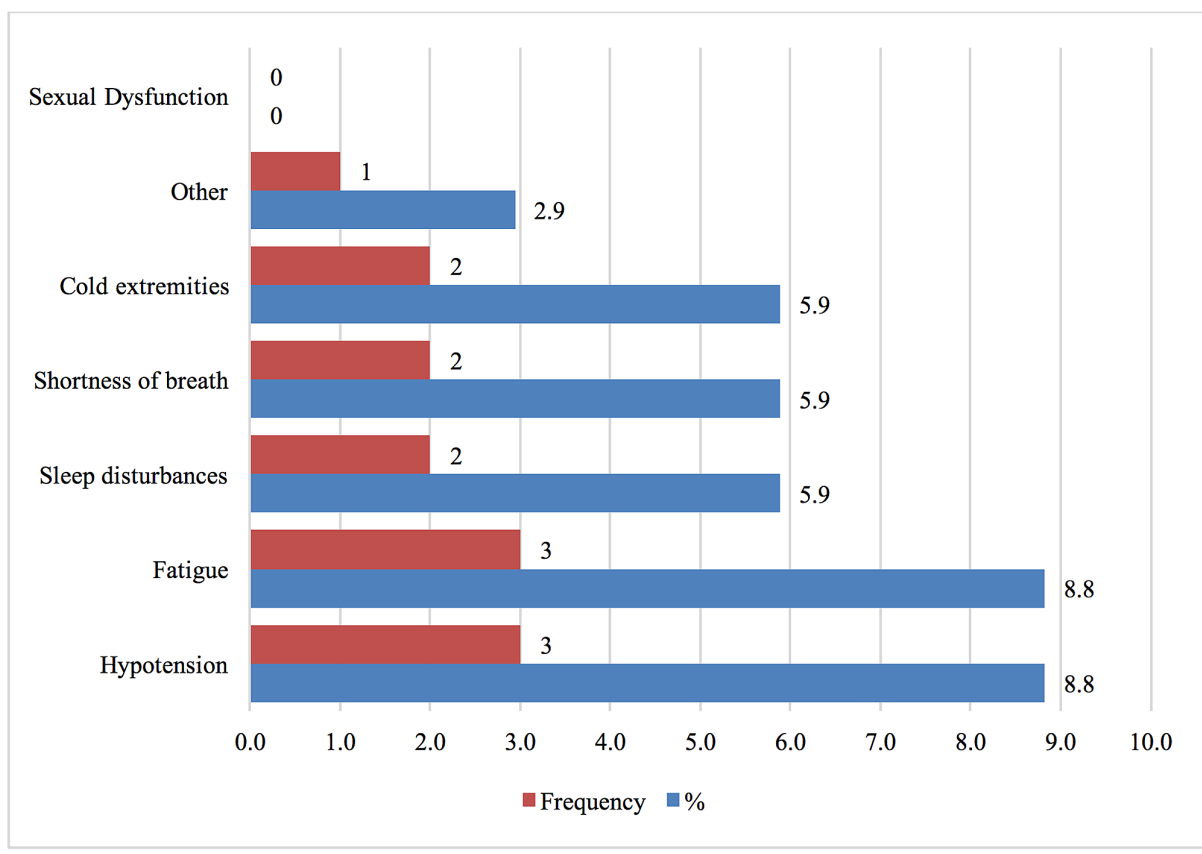

FIGURE 6: Side Effects Experienced With Using Propranolol

\section{Results of not using propranolol}

Of the 200 participants (85.5\%) who did not use propranolol, 53 (26.5\%) were recommended propranolol, and 31 (15.5\%) were offered propranolol.

\section{Discussion}

The prevalence of self-reported propranolol use among the studied sample of medical students at KSAU-HS was $14.4 \%$. Compared to a study conducted among university students in Switzerland [12], the prevalence 
was higher in our population, and it was found that $1.2 \%$ of students used beta-blockers for their psychoactive properties [12]. However, when our findings were compared with a study conducted from Saudi Arabia, it was found that $30 \%$ of medical and dental students at KSAU-HS used propranolol during their college years [13]. According to a German study conducted in a general population, $38.8 \%$ of people used psychoactive drugs for non-medical reasons such as coping with stress and cognitive performance enhancement [15]. Beta-blockers comprised (8.5\%) of the used drugs in that study [15].

It is apparent that the pattern of propranolol use among medical students is higher than the general population. This increased prevalence could be the result of medical students' knowledge of the drug from their study materials, and the varying levels of stress academically and socially. The discrepancies between the reported prevalence percentage of propranolol use among medical students can be attributed to the variation in samples between studies.

Most propranolol users in the sample reported taking the drug before OSCEs. The setting in the OSCEs may contribute to the anxiety associated with it, as every student is assessed for their skills and knowledge in different clinical scenarios. The numerous exam stations and time limitations per station (seven minutes) places pressure on students. As previously demonstrated in a study on medical students' perceptions of different examination methods, $63 \%$ of respondents reported that they find the OSCE very stressful, and $50 \%$ thought the time given was not enough [16]. Oral presentations were another occasion where participants reported using propranolol (38\%), which like OSCEs, include a social component. However, objective structured practical exams (OSPE; 8.8\%) and written exams (11.8\%) were minor reasons for propranolol use. Interestingly, half of the students who used propranolol in our study were in their fifth year, which is the year they start the clinical phase. This coincides with the introduction of OSCEs, which constitute a great portion of the grading system in the clinical years.

Social anxiety is more common among female students than males [17]. This can explain the increased pattern of propranolol use among females, as they used it for performance-enhancement purposes. This study has demonstrated a statistically significant higher propranolol use in females.

In addition to using propranolol, $58.8 \%$ have participated actively in recommending or offering it to other students. A considerable percentage of those who do not use propranolol reported being offered or recommended the drug by other students to use it. Such findings suggest the role peer pressure may play in propranolol use among students. It can also be indicative of a behavioral mannerism that normalizes using propranolol.

Drug restriction policies in pharmacies and accessibility vary in different countries, contributing to the varying percentages of use. A study covering six regions of Saudi Arabia found that only $63 \%$ of pharmacies adhered strictly to policies regarding prescription-only medications. Seventy-three percent of these pharmacies dispensed propranolol without a prescription, despite the listing of propranolol as a prescription drug by the Saudi Food and Drug Authority [18,19]. Students may decide to use drugs without a physician's assessment or prescription due to easy access through peers or directly from pharmacies. This might explain why only $35.3 \%$ of the users in our study had a physician's prescription for propranolol, which raises safety concerns about unsupervised use of this medication.

This study was limited by a small sample size that consisted of medical students at a single college. Generalizing these findings on the general population is not possible. This can be overcome in the future by conducting further research that includes other colleges and including a wider student population. Another limitation of our findings is the sample skewness, as the participants from various academic levels of college were not equally represented.

\section{Conclusions}

The prevalence of propranolol use among medical students in KSAU-HS Jeddah was low. Fifth-year medical students, in particular, have disproportionately reported the highest rates of propranolol use, accounting for $50 \%$ of all users. This increase may be attributed to the development of new stressors during the clinical phase of medical school. Furthermore, anxiety relief for OSCEs and presentations was the main reason for propranolol use. The majority of those who used propranolol were aware of its side effects. Nonetheless, it was most commonly self-prescribed. Educational entities should undertake initiatives towards raising medical students' awareness of the risks of unsupervised propranolol use. Medical students should also be encouraged to seek professional advice before using propranolol.

\section{Appendices \\ The consent form}




\section{Cureus}

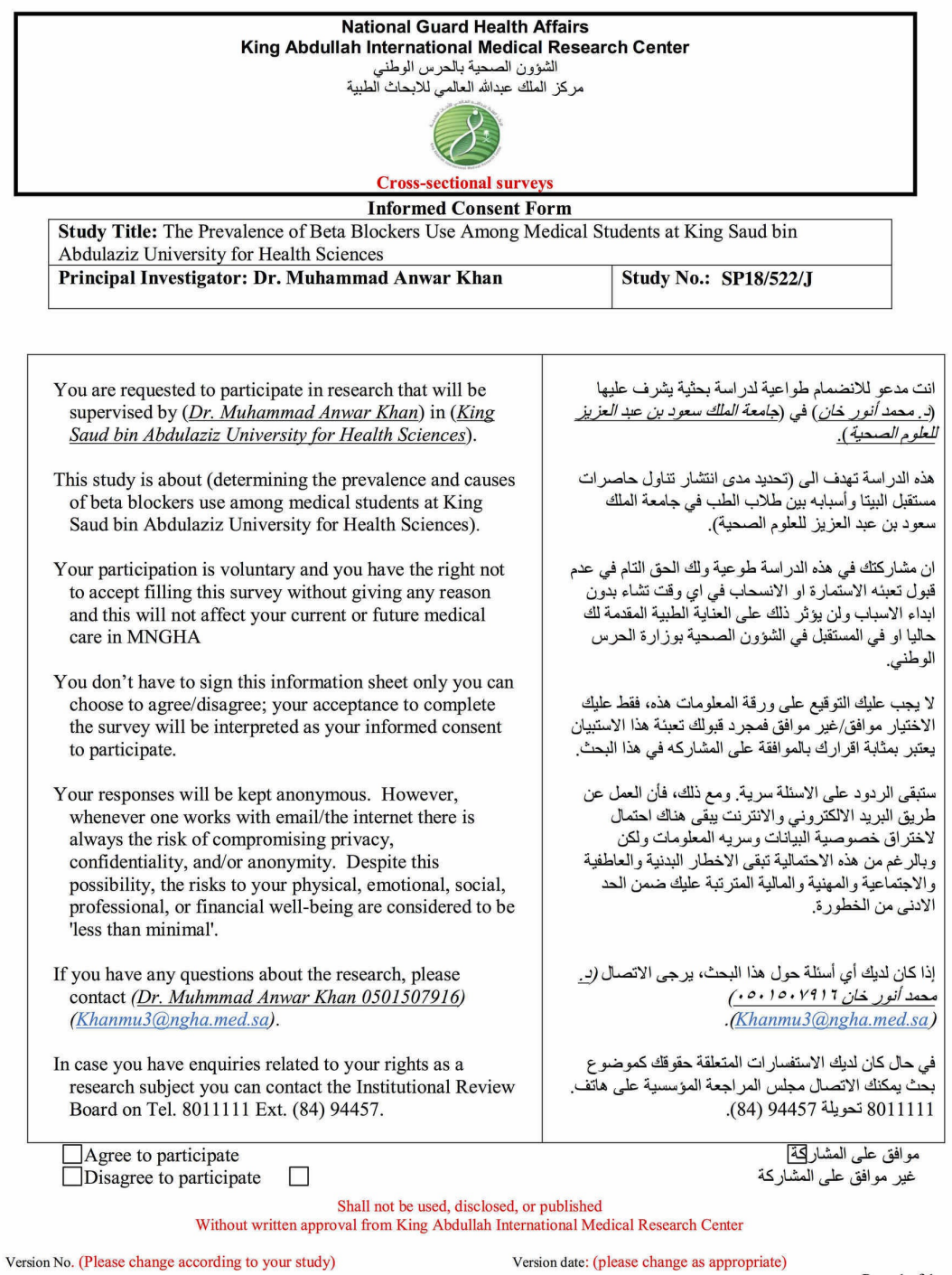

KAIMRC-RO/ICF SURVEYS BILINGUAL VERSION: 01 KAIMRC-RO/ ICF SURVEYS BILINGUAL VERSIO
Date: 15/05/2013 CROSS-SECTIONAL SURVEYS

FIGURE 7: Consent form

\section{The questionnaire}




\section{Cureus}

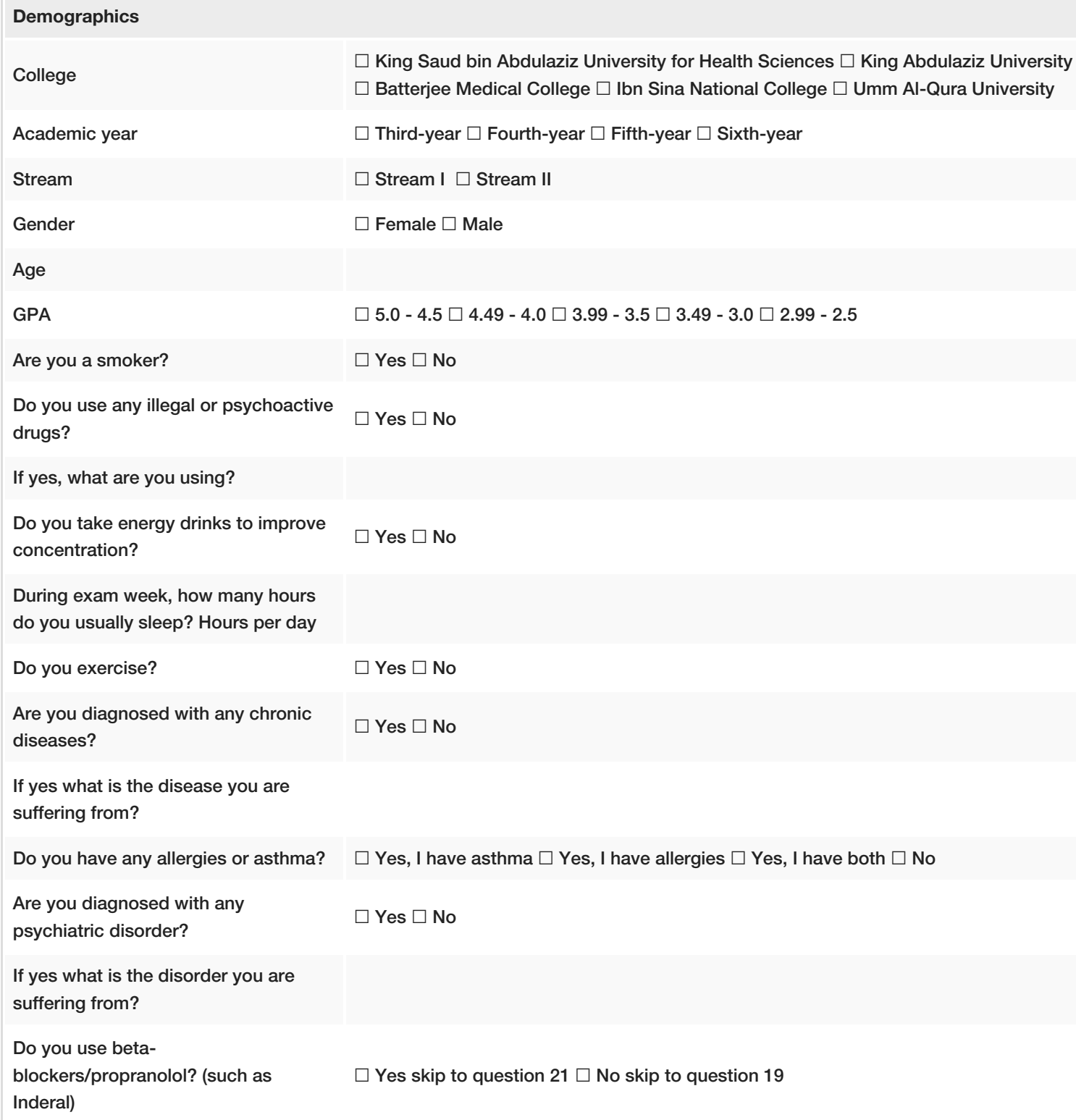

College

Academic year

Stream

Gender

Age

GPA

Are you a smoker?

Do you use any illegal or psychoactive drugs?

If yes, what are you using?

Do you take energy drinks to improve concentration?

During exam week, how many hours

do you usually sleep? Hours per day

Do you exercise?

$\square$ Yes $\square$ No

Are you diagnosed with any chronic diseases?

If yes what is the disease you are suffering from?

Do you have any allergies or asthma?

Are you diagnosed with any

psychiatric disorder?

$\square$ King Saud bin Abdulaziz University for Health Sciences $\square$ King Abdulaziz University

$\square$ Batterjee Medical College $\square$ Ibn Sina National College $\square$ Umm Al-Qura University

$\square$ Third-year $\square$ Fourth-year $\square$ Fifth-year $\square$ Sixth-year

$\square$ Stream I $\square$ Stream II

$\square$ Female $\square$ Male

$\square 5.0$ - $4.5 \square 4.49$ - $4.0 \square 3.99$ - $3.5 \square 3.49$ - $3.0 \square 2.99$ - 2.5

$\square$ Yes $\square$ No

$\square$ Yes $\square$ No

$\square$ Yes $\square$ No

$\square$ Yes $\square$ No

$\square$ Yes, I have asthma $\square$ Yes, I have allergies $\square$ Yes, I have both $\square$ No

$\square$ Yes $\square$ No

$\square$ Yes skip to question $21 \square$ No skip to question 19

blockers/propranolol? (such as

Inderal)

TABLE 3: Section 1

Beta-Blockers Use

Were you ever recommended beta-blockers/propranolol?

$\square$ Yes $\square$ No

Were you ever offered beta-blockers/propranolol?

$\square$ Yes $\square$ No

END OF QUESTIONNAIRE

TABLE 4: Section 2 


\section{Cureus}

Beta-Blockers Use

How did you know about beta-

blockers? Check all that applies.

Who prescribed propranolol to you?

How frequently do you use propranolol?

What is the dose taken per intake?

Do you increase the dose without physician instructions?

Why do you use propranolol? Check all that applies.

When do you use Propranolol? Check all that applies.

Are you aware of the side effects of the unsupervised use of Propranolol?

If yes, what are the side effects you know? Check all that applies.

Did you experience any side effects?

If yes, what are the side effects you experienced? Check all that applies

Do you think it improves your performance?

Did a friend or a classmate ever

recommend propranolol to you?

Did you ever offer propranolol to a friend or classmate?

Would you recommend propranolol to anyone?

END OF QUESTIONNAIRE $\square$ Social Media $\square$ Internet surfing $\square$ Friends and classmates $\square$ Family $\square$ Study material

$\square$ Prescribed by a physician $\square$ Yourself $\square$ Friend $\square$ Family member

$\square<10 \mathrm{mg} \square 10-20 \mathrm{mg} \square 30-40 \mathrm{mg} \square>40 \mathrm{mg}$

$\square$ Yes $\square$ No

$\square$ Performance enhancement $\square$ Anxiety relief $\square$ Peer pressure $\square$ Other

$\square$ Before written exams $\square$ Before OSCE $\square$ Before OSPE $\square$ Before presentations $\square$ During exams period (studying) $\square$ Social gatherings $\square$ Other

$\square$ Yes $\square$ No

$\square$ Hypotension $\square$ Sexual dysfunction $\square$ Fatigue $\square$ Sleep disturbances $\square$ Shortness of breath $\square$ Cold extremities $\square$ Other

$\square$ Yes $\square$ No

$\square$ Hypotension $\square$ Sexual dysfunction $\square$ Fatigue $\square$ Sleep disturbances $\square$ Shortness of breath $\square$ Cold extremities $\square$ Other:

$\square$ Yes $\square$ No

$\square$ Yes $\square$ No

$\square$ Yes $\square$ No

$\square$ Yes $\square$ No

\section{TABLE 5: Section 3}

\section{Additional Information \\ Disclosures}

Human subjects: Consent was obtained by all participants in this study. King Abdullah International Medical Research Center (KAIMRC) issued approval SP18/522/J. Animal subjects: All authors have confirmed that this study did not involve animal subjects or tissue. Conflicts of interest: In compliance with the ICMJE uniform disclosure form, all authors declare the following: Payment/services info: All authors have declared that no financial support was received from any organization for the submitted work. Financial relationships: All authors have declared that they have no financial relationships at present or within the previous three years with any organizations that might have an interest in the submitted work. Other relationships: All authors have declared that there are no other relationships or activities that could appear to have influenced the submitted work.

\section{References}

1. Farrell S, Kadhum M, Lewis T, Singh G, Penzenstadler L, Molodynski A: Wellbeing and burnout amongst medical students in England. Int Rev Psychiatry. 2019, 31:579-83. 10.1080/09540261.2019.1675960

2. Hill MR, Goicochea S, Merlo LJ: In their own words: stressors facing medical students in the millennial generation. Med Educ Online. 2018, 23:1530558. 10.1080/10872981.2018.1530558

3. Kötter T, Wagner J, Brüheim L, Voltmer E: Perceived medical school stress of undergraduate medical students predicts academic performance: an observational study. BMC Med Educ. 2017, 17:256. 10.1186/s12909-017-1091-0

4. Al-Dabal BK, Koura MR, Rasheed P, Al-Sowielem L, Makki SM: A comparative study of perceived stress 
among female medical and non-medical university students in Dammam, Saudi Arabia. Sultan Qaboos Univ Med J. 2010, 10:231-40.

5. Bunevicius A, Katkute A, Bunevicius R: Symptoms of anxiety and depression in medical students and in humanities students: relationship with big-five personality dimensions and vulnerability to stress. Int J Soc Psychiatry. 2008, 54:494-501. 10.1177/0020764008090843

6. Rotenstein L, Ramos M, Torre M, et al.: Prevalence of depression, depressive symptoms, and suicidal ideation among medical students: a systematic review and meta-analysis. JAMA. 2016, 316:2214-36. 10.1001/jama.2016.17324

7. Mazurkiewicz R, Korenstein D, Fallar R, Ripp J: The prevalence and correlations of medical student burnout in the pre-clinical years: a cross-sectional study. Psychol Health Med. 2012, 17:188-95. 10.1080/13548506.2011.597770

8. Faigel H: The effect of beta blockade on stress-induced cognitive dysfunction in adolescents . Clin Pediatr (Phila). 1991, 30:441-5. 10.1177/000992289103000706

9. Pharmacotherapy for social anxiety disorder in adults . (2020). Accessed: November 11, 2020: https://www.uptodate.com/contents/pharmacotherapy-for-social-anxiety-disorder-in-adults .

10. Steenen SA, van Wijk AJ, van der Heijden GJ, van Westrhenen R, de Lange J, de Jongh A: Propranolol for the treatment of anxiety disorders: systematic review and meta-analysis. J Psychopharmacol. 2016, 30:128-39. 10.1177/0269881115612236

11. Hayes PE, Schulz SC: Beta-blockers in anxiety disorders. J Affect Disord. 1987, 13:119-30. 10.1016/01650327(87)90017-6

12. Maier LJ, Liechti ME, Herzig F, Schaub MP: To dope or not to dope: neuroenhancement with prescription drugs and drugs of abuse among Swiss university students. PLoS One. 2013, 8:e77967. 10.1371/journal.pone.0077967

13. Al-Mohrej O, Al-Bani W, AlShalaan N, Aldahash R, Alyamani A, Almodaimegh H: Prevalence of selfprescribing propranolol among medical and dental students in Riyadh, Saudi Arabia: a cross-sectional Study. Health Prof Educ. 2018, 4:16-26. 10.1016/j.hpe.2016.10.001

14. Leaute-Labreze C, Boccara O, Degrugillier-Chopinet C, et al.: Safety of oral propranolol for the treatment of infantile hemangioma: a systematic review. Pediatrics. 2016, 138:e20160353. 10.1542/peds.2016-0353

15. Bagusat C, Kunzler A, Schlecht J, Franke A, Chmitorz A, Lieb K: Pharmacological neuroenhancement and the ability to recover from stress: a representative cross-sectional survey among the German population. Subst Abuse Treat Prev Policy. 2018, 13:37. 10.1186/s13011-018-0174-1

16. Dadgar SR, Saleh A, Bahador H, Baradaran HR: OSCE as a tool for evaluation of practical semiology in comparison to MCQ \& oral examination. J Pak Med Assoc. 2008, 58:506-7.

17. Social anxiety disorder. (2018). Accessed: June 10, 2020: https://bestpractice.bmj.com/topics/en-us/1120.

18. Alshammari T, Alhindi S, Alrashdi A, Benmerzouga I, Aljofan M: Pharmacy malpractice: the rate and prevalence of dispensing high-risk prescription-only medications at community pharmacies in Saudi Arabia. Saudi Pahrm J. 2017, 25:709-14. 10.1016/j.jsps.2016.10.001

19. Propranolol drug details. (2020). Accessed: July 13, 2020: https://old.sfda.gov.sa/en/drug/search/Pages/drugdetails.aspx?did=3373\&sm=human. 